\title{
СПОСОБЫ СНИЖЕНИЯ СТОИМОСТИ РЕКОНСТРУКЦИИ ПРОМЫШЛЕННЫХ ЗДАНИЙ
}

\author{
(c) 2020 Толстихина Екатерина Дмитриевна
}

студент магистратуры кафедры строительные материалы и технологий строительства

Сибирский федеральный университет, Россия, Красноярск

E-mail: tolstihina@yandex.ru

\section{(c) 2020 Брыжатый Даниил Ринатович}

студент магистратуры кафедры строительные материалы и технологий строительства

Сибирский федеральный университет, Россия, Красноярск

E-mail: bruzhatui@yandex.ru

(c) 2020 Шмидт Максим Ильич

студент специалитета кафедры «Строительство уникальных зданий и сооружений»

Сибирский федеральный университет, Россия, Красноярск

E-mail: maks.shmidt.01@list.ru

(c) 2020 Кудусов Абдурахмон Абдусаломович

студент кафедры инженерных систем зданий и сооружений

Сибирский федеральный университет, Россия, Красноярск

E-mail: qudusov2002@mail.ru

\section{(c) 2020 Кременская Екатерина Александровна}

студент специалитета кафедры «Строительство уникальных зданий и сооружений»

Сибирский федеральный университет, Россия, Красноярск

E-mail: ekaterina.kremenskaya@gmail.com

На сегодняшний день реконструкция промышленных предприятий является одним из главных факторов решения проблемы отсталости промышленности в России. Воспроизводство основных фондов промышленных предприятий способствует росту промышленного предпринимательства, увеличению конкурентоспособности произведенной продукции не только на российском, но и на международном рынках, что приведет к экономическому развитию страны в целом.

В статье рассматриваются способы снижения стоимости реконструкции основных фондов промышленных предприятий.

Ключевые слова: реконструкция, способы снижения стоимости, строительство, экономия, промышленные здания

Оценка экономической эффективности промышленных зданий становится все более актуальной задачей, это объясняется теоретическими, методическими и практическими отличительными чертами.

Стоимость созданного путем реконструкции объекта может в несколько раз превосходить расходы, затраченные на проектирование, согласование и строительные работы нового здания или сооружения.

Реконструкция объекта - многогранный процесс, состоящий не только из внешних мероприятий (строительных работ), но и из экономического анализа, оценки эффективности технологий и материалов. Поэтому тема снижения стоимости реконструкции промышленных предприятий актуальна.

Сегодня реконструкция действующих производственных зданий зачастую связаны с внушительными объемами строительства, которые характеризуются большими трудозатратами, продолжительностью и высокой стоимостью. В силу того, что большинство заказчиковзастройщиков не обладают профессиональным опытом, им приходится решать проблему выбора подходящего способа капитального строительства, который включает в себя организацию строительно-монтажных работ, управление 
строительными проектами и т.д.

Количество введенных промышленных зданий в Российской Федерации в период с 2011 по 2019 год остается в диапазоне 2500-3500 единиц. По этим данным можно сделать вывод о том, что объемы промышленных зданий в нашей стране не уменьшаются. В связи с этим, потребность в реконструкции действующих предприятий может возникнуть через 5-10 лет после их введения в эксплуатацию.

На сегодняшний день нормативнотехническая литература в большей степени сфокусирована на регулировании строительных и жилищно-коммунальных процессов, и к сожалению, в ней не учитывается специфичность и сложности в организации реконструкции промышленных предприятий. Вследствие этого, составление плана и подготовка капитального строительства в данных условиях требует высоких управленческих качеств, а также соблюдение корпоративной стратегии в отношении инвестиционной и производственной программ.

Следствием отсутствия опыта и наличия неразвитой нормативной базы строительства и реконструкции промышленных предприятий является завышение стоимости СМР и большой продолжительностью производства работ. Все это приводит к неэффективности реализуемых строительных проектов, а так же является преградой для развития конкурентоспособности промышленных предприятий и их продукции.

Строительство и реконструкция промышленных предприятий согласно с установленной классификацией могут осуществляться с применением трех главных способов организации капитального строительства: подрядного, хозяйственного и смешанного. Данные методы основаны на степени участия подрядчика. Выбор способа зависит от различных факторов и внешних условий.

Наибольшее внимание исследователей посвящено подрядному способу, который предполагает осуществление строительно-монтажных работ (СMP) внешними профессиональными строительными организациями (подрядчиками) на договорной основе.

Хозяйственный способ предусматривает выполнение СМР собственными силами в качестве одного из видов собственной деятельности без привлечения внешних подрядчиков на договорной основе.

Смешанный способ предполагает сочетание двух указанных подходов, в котором одна часть строительных работ осуществляется собственными силами, а другая с помощью привлечения подрядной организации [1].

Приведем сравнительную характеристику указанных способов организации капитального строительства с точки зрения потенциала снижения стоимости и сокращения сроков строительства и реконструкции основных фондов.

Подрядный способ организации СМР чаще всего применяется на практике. Он реализуется в рамках вида деятельности «строительство». Объём работ, выполненных по данному виду деятельности, в декабре 2019 года составил 8503,3

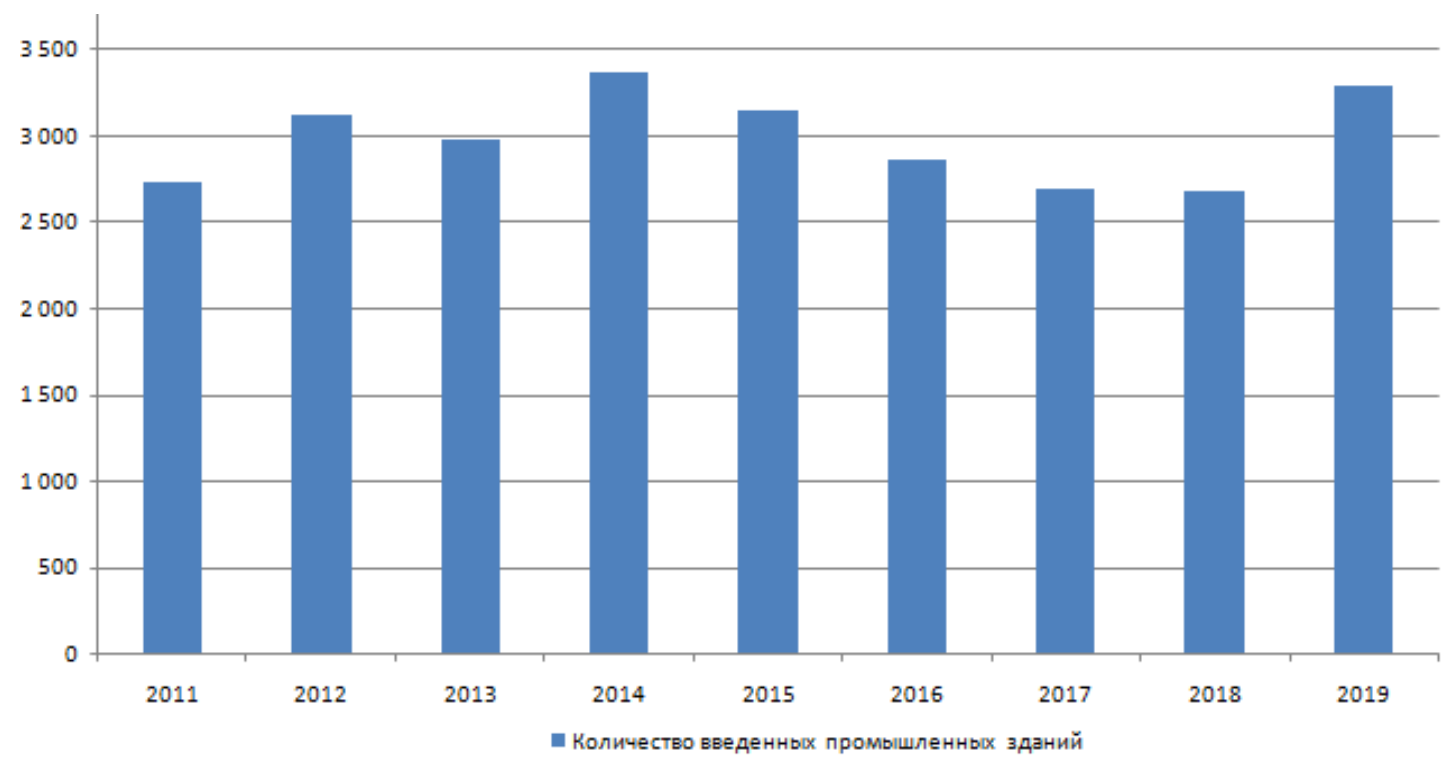

Рисунок 1. Количество введенных промышленных зданий в период с 2011 по 2019 гг. 
млн. руб. По данным на апрель 2020 г., этот показатель равен 182,3 млн. руб., что составляет 54,5\% к уровню за тот же период времени 2019 года [2].

Некоторые исследователи считают, что подрядный способ характеризуется высокой степенью индустриализации производства строительно-монтажных работ, использованием современных строительных технологий, машин и механизмов, а также профессионализмом исполнителей. В исторической ретроспективе доля этого способа в общем объеме СMP непрерывно возрастала.

Использование подрядного способа организации СМР в процессе строительства и реконструкции предприятия приводит к появлению дополнительных затрат по сравнению с хозяйственным способом. Вместе с необходимостью покрытия прибыли и рисков привлекаемого подрядчика, существенные издержки возникают в связи с выходом на рынки подрядных работ, участие в которых в соответствии с теорией транзакционных издержек не является бесплатным. Размер транзакционных издержек зависит от вида деятельности и особенностей сделок и может достигать $10 \%$ от оборота компаний, ра- ботающих на свободном рынке.

Применительно к деятельности предприятий по строительству и реконструкции основных фондов полное устранение транзакционных издержек может быть достигнуто путем включения в состав предприятия строительных компаний (интеграции) либо путем выполнения СМР хозяйственным способом.

Уменьшение затрат на транзакцию возможно при применении партнерства в процессе подрядных отношений. В процессе организации подрядных работ в проектах строительства и реконструкции партнерские отношения дают возможность улучшить временные и стоимостные показатели за счет уменьшения затрат на транзакцию, а также благодаря использованию совместных усилий партнеров, сокращения разногласий и обеспечении обмена информации между партнерами.

Хозяйственный способ организации СМР применяется не так часто, как подрядный метод. По мнению исследователей, популярность использования этого способа в 80-е годы прошлого века связана с переводом предприятий на полный хозяйственный расчет и самофинансирование, а также привлечением населения и

\begin{tabular}{|c|c|c|c|}
\hline & \multirow{2}{*}{ 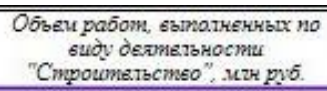 } & \multicolumn{2}{|c|}{$\bar{B} \% \mathrm{~K}$} \\
\hline & & 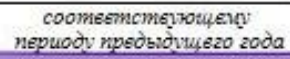 & $\begin{array}{l}\text { npedbidvweray } \\
\text { nepuody }\end{array}$ \\
\hline \multicolumn{4}{|c|}{2019} \\
\hline /reapb & 214,6 & 138,7 & 21,1 \\
\hline Феврап & 148,7 & 53,5 & 68,8 \\
\hline Mapt & 200,3 & 77,0 & 133,7 \\
\hline I кGapmar & 563,6 & 81,5 & - \\
\hline Anpers & 333,4 & 87,7 & 165,8 \\
\hline Январь-апрепь & 897,0 & 83,7 & - \\
\hline Май & 806,3 & 71,0 & $=2,4 p$ \\
\hline Июонь & 1563,3 & 97,7 & 191,4 \\
\hline II көapmar & 2703,0 & 86,7 & - \\
\hline Янбарь-июнн & 3266,6 & 85,7 & - \\
\hline Иromb & 1470,8 & 114,2 & 93,3 \\
\hline Aeryer & 150,3 & 9,6 & 10,1 \\
\hline Cентябри & 933,2 & 66,3 & $=6,1 \mathrm{p}$ \\
\hline III кsapmat & 2554,3 & 60,0 & - \\
\hline Янбарь-сентяборь & 5820,9 & 72,3 & - \\
\hline Okтaбps & 1142,0 & 162,0 & 121,5 \\
\hline Нохбри & 563,9 & 102,4 & 49,1 \\
\hline Дexa6бps & 976,5 & 88,4 & 172,3 \\
\hline$I V_{\text {Keapma }}$ & 2682,4 & 113,8 & - \\
\hline 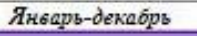 & 8503,3 & 81,4 & - \\
\hline \multicolumn{4}{|c|}{2020} \\
\hline Freapb & 71,3 & 37,3 & 8,7 \\
\hline Февраль & 95,2 & 62,8 & 132,2 \\
\hline Mapt & 251,6 & 124,7 & $=2,6 \mathrm{p}$ \\
\hline I k6apma & 418,1 & 73,4 & - \\
\hline Anpert & 182,3 & 54,5 & 72,4 \\
\hline fiнварь-апрель & 600,4 & 66,4 & - \\
\hline
\end{tabular}

Рисунок 2. Динамика объема работ, выполненных по виду деятельности «строительство» 
трудовых коллективов к строительству жилых домов и социально-бытовых объектов. Однако с переходом к рыночным отношениям эта доля упала и снова стала увеличиваться с 2000 года в связи с ростом объемов работ по модернизации производства в различных отраслях.

Специалисты считают, что хозяйственный способ обладает следующими особенностями:

- данный метод используется в в ходе осуществления строительных работ для собственных потребностей;

- согласно нормативно-правовой литературе, промышленное предприятие выполняет роль застройщика («физическое или юридическое лицо, обеспечивающее на принадлежащем ему земельном участке строительство, реконструкцию, капитальный объектов капитального строительства, а также ремонт выполнение инженерных изысканий, подготовку проектной документации для их строительства, реконструкции, капитального ремонта») [3];

- выполняется силами собственных структурных подразделений и штатных работников, а при необходимости и работников, привлеченных на гражданско-правовой основе;

- регулирование взаимоотношений осуществляется на основе внутрихозяйственного заказа при полном отсутствии договорных отношений между предприятием и его структурными подразделениями, привлекаемыми к выполнению СМР;

- во время выполнения СМР предприятие создает производственную базу, которая включает собственные и взятые в аренду машины и механизмы.

В связи с последним пунктом следует отметить, что ряд исследователей считают, что для успешной реализации хозяйственного способа формируемая производственная база и профессиональные строительные подразделения (управления или отделы капитального строительства и аналогичные) должны функционировать в течение длительного периода времени, то есть применение хозяйственного способа целесообразно, если СМР ведутся на постоянной или регулярной основе.

Получается, что хозяйственный способ применим для строительных объектов с небольшим объемом работ, чаще всего его используют в процессе реконструкции главных фондов, а так же в случаях, когда место строительства территориально удалено от района работы профиль- ных подрядчиков.

Смешанный способ включает в себя характеристики хозяйственного и подрядного способов, тем самым достигается снятие ограничений, которые свойственны каждому из этих методов. По итогу, трудоемкие и специфичные виды работ (строительство новых объектов, установка промышленного оборудования, монтаж очистных сооружений) рационально отдать на подрядные работы, а более простые задачи такие как расширение площади существующих помещений, отделка, обустройство территории, возможно выполнить благодаря хозяйственному методу. Применение смешанного способа так же целесообразно когда часть работ необходимо выполнить для собственных потребностей, а другую часть под заказ у внешних организаций.

Для учета специфики проектов строительства и реконструкции основных фондов действующего предприятия, отличающихся большим разнообразием, предлагаем рассматривать подрядный способ организации капитального строительства как включающий несколько вариантов реализации:

1) подрядные работы. Этот метод предусматривает закупку работ подряда на свободном строительном рынке, здесь особую роль играет метод и процесс выбора подрядчика, условий, прописанных в договоре, а также следует уделять внимание мероприятиям, которые направлены на сокращение транзакционных затрат;

2) заключение партнерских отношений, которые оформляются благодаря одному из трех описанных методов: на фиксированный срок, на один проект или на дальнейшие проекты;

3) интеграция, предусматривающая формирование в составе интегрированной структуры строительных, инжиниринговых и иных компаний, необходимых для ведения СМР.

Правильный выбор метода организации всего строительного процесса при реконструкции главных фондов промышленного предприятия необходимо рассматривать в качестве самого важного фактора, от которого зависит возможность снижения стоимости и продолжительности строительства [4].

Подрядная организация за счет более высокой технологичности производимых работ имеет преимущество перед предприятием, выполняющим СМР хозяйственным способом, то есть расчетная себестоимость работ, выполняемых подрядным способом, скорее всего будет ниже, 
чем себестоимость тех же работ, выполняемых хозяйственным способом. Необходимо отметить, что при конкурентной системе выбора подрядчика у него имеется важный стимул для снижения себестоимости повышение конкурентоспособности конкурсной заявки. Такая мотивация отсутствует у подрядчика, привлекаемого на партнерской основе, соответственно, себестоимость СМР с большой долей вероятности будет оценена им выше, чем у подрядчика, выбираемого через торги, и может быть сравнима с себестоимостью СМР, выполняемых хозяйственным способом [5].

В то же время полная расчетная стоимость строительства с большой долей вероятности будет ниже при организации выполнения СМР хозяйственным способом, чем любым из двух видов подряда ввиду отсутствия в расчете стоимости строительства хозяйственным способом затрат на прибыль и риск, точнее их невыделение из соответствующей статьи затрат предприятия в целом

По мнению российских и иностранных исследователей, фактическая стоимость выполненных подрядчиком работ выше, в сравнении с ценой, указанной в договоре. Это происходит за счет дополнительных выплат подрядчику по компенсационным статьям, расходов на доарбитражное и арбитражное урегулирование споров и прочих дополнительных издержек [6].

Далее приведем сравнение достоинств и не- достатков хозяйственного и подрядного способа. В анализе не будет учтен смешанный способ, так как в нем присутствуют черты каждого из двух методов.

В сокращении сроков строительства заинтересован как инвестор строительного объекта, так и подрядчик. Следствием уменьшения продолжительности стройки для заказчика является получение прибыли от раннего ввода строительного объекта в эксплуатацию, а также экономию на стоимости кредита. А для подрядчика, сокращение сроков строительства приведет к получению дополнительного дохода и уменьшению накладных расходов. В итоге, сокращение продолжительности строительства выгодно обеим сторонам.

Для оптимизации издержек, затраченных на организацию строительных подразделений, в непрофильных предприятиях исследователями была предложена модификация хозяйственного способа производства СМР, которая основана на объединении средств нескольких юридических лиц и подразумевающая создание отделов строительства, являющихся общими для нескольких предприятий. Авторы предлагают называть такой вид организации работ строительным краудфандингом. Это определение включает в себя коллективное участие людей в проекте на основе добровольного объединения своих ресурсов, в числе которых финансовые.

Строительный краудфандинг подразуме-

Таблица 1. Достоинства и недостатки подрядного и хозяйственного способов

\begin{tabular}{|c|c|c|}
\hline Способ/характеристика & Достоинства & Недостатки \\
\hline Подрядный способ & $\begin{array}{l}\text { 1. Приемлимое соотношение стоимости } \\
\text { и качества работ благодаря выбору под- } \\
\text { рядчика на конкурсной основе. } \\
\text { 2. Возможность использования совре- } \\
\text { менных технологий, инновационных } \\
\text { материалов и выполнение работ опыт- } \\
\text { ными квалифицированными работни- } \\
\text { ками } \\
\text { 3. Возможность привлечения специали- } \\
\text { стов в узкой специализации в качестве } \\
\text { субподрядчика, что позволит выполнить } \\
\text { работу различной сложности }\end{array}$ & $\begin{array}{l}\text { 1. Высокие издержки, возникающие в } \\
\text { результате поиска и выбора подходящей } \\
\text { подрядной организации. } \\
\text { 2. Вероятность разногласий между под- } \\
\text { рядчиком и заказчиком как в процессе } \\
\text { выполнения работа, та и после заверше- } \\
\text { ния строительства. } \\
\text { 3. Сложность в координации строитель- } \\
\text { ных работ с процессами производства } \\
\text { на в случае реконструкции действующе- } \\
\text { го предприятия. }\end{array}$ \\
\hline Хозяйственный способ & $\begin{array}{l}\text { 1. Возможность экономии затрат бла- } \\
\text { годаря сокращению транзакционных } \\
\text { издержек. } \\
\text { 2. Удобство в координации выполнения } \\
\text { СМР и основных процессов производ- } \\
\text { ства на предприятии. } \\
\text { 3. Возможность выполнения строитель- } \\
\text { ных работ в условиях ограниченного } \\
\text { бюджета. }\end{array}$ & $\begin{array}{l}\text { 1. Данный метод целесообразней } \\
\text { использовать для крупных, ложных, } \\
\text { высокотехнологичных объектов. } \\
\text { 2. Высокие затраты на создание стро- } \\
\text { ительного подразделения в непро- } \\
\text { фильной организации, а так же на его } \\
\text { формирование и содержание. } \\
\text { 3. Отсутсвие возможности применения } \\
\text { передовых технологий строительства и } \\
\text { новых материалов. }\end{array}$ \\
\hline
\end{tabular}


вает совокупность ресурсов различных непрофильных предприятий для производства СМР и реализации инвестиционно-строительных проектов, в число которых может входить реконструкция промышленных зданий. В этой ситуации благотворительность не предусматривается, в данном виде краудфандинга принимают участие только те юридические лица или предприниматели, которые заинтересованы в реализации проекта.

Отделение строительного краудфандинга должно постоянно функционировать в случае, если участники непрерывно или временно ведут строительно-монтажные работы. Если же подразделение создано для реализации какого-либо определенного проекта, то в такая ситуация уместна, когда в осуществлении инвестиционностроительного проекта заинтересованы все участники строительного краудфандинга. Примером такой организации может служить строительство социальных объектов, которые находятся в собственности юридического лица (база отдыха, детский сад и т.д.). В этом случае объект строительства может находиться в кондоминиуме членов строительного краудфандинга. Использование данного вида организации строительства даст возможность не только уменьшить расходы участников проекта, но также позволит консолидироваться организациям-участникам.

К сожалению, на данный момент использование строительного краудфандинга не возможно, в силу отсутствия нормативно-правовой базы. Но есть возможность рассмотреть такой вид сотрудничества в рамках картельных соглашений для реализации совместных инвестиционностроительных проектов, или с помощью участия в деятельности иных организаций. В этом случае права всех членов будут регламентированы в рамках инвестиционно-строительного проекта. Ответственность по результатам реализации будет распределена между участниками согласно их доле участия в проекте.

Подводя итог, на стоимость реконструкции основных фондов промышленных предприятий, осуществляющих свою деятельность, влияет выбор способа организации работ по капитальному строительству. Выбор, осуществляемый между хозяйственным методом, тремя вариациями подрядного способа, смешанной организации строительно-монтажных работ, а также вид сотрудничества для реализации совместных инвестиционно-строительных проектов. Кроме этого, важным фактором уменьшения стоимости реконструкции является сокращение сроков строительных работ.

Для сокращения стоимости реконструкции необходимо учесть множество факторов, исходя из которых, выбрать подходящую под заданные условия организационную структуру, после этого выполнить анализ различных альтернатив и найти выгодное решение.

\section{Библиографический список}

1. Бирюков А.Н. Основы организации экономики и управления в строительстве: учебное пособие. М.Спецстрой РФ, 2012.

2. Росстат. Строительная деятельность [Электронный ресурс] URL: https://rosstat.gov.ru/region/docl1184/ IssWWW.exe/Stg/2020/1.37.2_04/07.htm (Дата обращения 20.08.2020)

3. Градостроительный кодекс Российской Федерации: Федер. закон [принят Гос. Думой 22 декабря 2004 г; одобр. Советом Федерации 24 декабря 2004 г] // Российская газета. 30 дек. 2004.

4. Петров Ф.И. Повышение эффективности реализации инвестиционного проекта реконструкции промышленных предприятий / Ф.И.Петров // Строительная механика инженерных конструкций и сооружений.2008 - № 2 - с. $70-72$

5. Чурбанов А.Е. Формирование механизма подрядных договорных отношений в современном строительстве: дис. ... канд. экон. наук. СПб. 2006.

6. Пучнина А. С, ТарасоваЕ.Н. Организация, планирование и управление в строительстве: сборник лекций. Хабаровск: изд-во ДВГУПС, 2013.

7. Росстат: объем строительных работ за первое полугодие 2020 года снизился на 0,5\% (график) [Электронный ресурс] URL: https://erzrf.ru/news/rosstat-obyem-stroitelnykh-rabot-za-pervoye-polugodiye-2020-godasnizilsya-na-05-grafik?costType=1 (Дата обращения 20.08.2020) 